\title{
The Role of Emotional Intelligence in Relieving Work Pressure for Practice Nurses: A Cross-sectional Study
}

\author{
Shujuan Xu", Shenghong He, Meihong Zeng, Huahua Chen \\ Nursing Department, Yijishan Hospital, Wannan Medical College, Wuhu, China \\ Email address: \\ 485227129@qq.com (ShujuanXu),459974865@qq.com (Shenghong He),2964326481@qq.com (Meihong Zeng), \\ 2414693502@qq.com (Huahua Chen) \\ ${ }^{*}$ Corresponding author
}

\section{To cite this article:}

Shujuan Xu, Shenghong He, Meihong Zeng, Huahua Chen. The Role of Emotional Intelligence in Relieving Work Pressure for Practice Nurses: A Cross-sectional Study. American Journal of Nursing Science. Vol. 8, No. 2, 2019, pp. 36-42. doi: 10.11648/j.ajns.20190802.11

Received: December 27, 2018; Accepted: January 21, 2019; Published: March 1, 2019

\begin{abstract}
EI involves the ability to relate to and influence others, and may be important for practice nurses. A questionnaire survey was conducted among 96 nurses who had just completed their internship period. The main work pressures experienced by practice nurses were analyzed. To investigate and analyze the main work pressures on clinical practice nurses, and improve their emotional literacy through targeted emotional intelligence (EI) education to support good professional quality and active responses to work stress. In total, 102 new practice nurses were randomly divided into control and experimental groups. Both groups received routine professional skill training. Nurses in the experimental group also received guided EI training. Working pressure and EI level were tested in both groups before and after the internship period. The main work pressures on practice nurses were excessive nursing workloads and poor allocation of work time. The experimental group had higher EI scores and lower pressure scores than the control group. EI education for practice nurses may be particularly important in relieving work pressures.
\end{abstract}

Keywords: Emotional Intelligence, Practice Nurses, Work Pressure

\section{Introduction and Background}

There has been continuous improvement in medical care along with growing demand for health services over recent years. Nurses are required to have good business skills, as well as a high level of emotional literacy. This enables them to provide comprehensive physical, psychological, and social care and help for their patients. However, nursing is recognized internationally as one of the most stressful professions [1], as shown by the exceedingly high rate of burnout among nursing professionals [2]. Major sources of stress for nurses include insufficient skills, shift work, fear of committing errors or being accused of negligence, power differentials, lack of peer and/or organizational support, heavy workloads, and conflict with other healthcare professionals, patients, and their families [3, 4]. These stressors may make it challenging for nurses to provide high levels of nursing services.

Practice nurses who have just started working in a hospital also face these stressors. In addition, practice nurses may be more likely to experience stress and pressure. This may be exacerbated by the sudden transition from a "relaxed" state of study and student life to complex, busy clinical nursing work. New nurses that do not have a mature state of mind, ability to cope with stress, optimistic attitudes toward life, and tolerance for setbacks may experience greater pressure and potentially bring harm to themselves, their patients, and their hospitals [5, 6]. Therefore, it is one of the important tasks for nursing educators to understand the sources of stress for practice nurses and to guide them to adopt appropriate countermeasures to alleviate or relieve psychological stress, so as to maintain physical and mental health and improve the effect of practice.

Emotional Intelligence (EI) is defined as "the ability to perceive emotions, to access and generate emotions so as to assist thought, to understand emotions and emotional meanings, and to reflectively regulate emotions so as to promote both better emotional and intellectual growth" [7]. High EI has been linked to higher performance in the 
workplace, higher job satisfaction, and less burnout. Practice nurses who demonstrate a combination of technical skills and EI may also be more attuned to the humanity aspect of healthcare. Practice nurses who value providing holistic care for their patients may already possess many elements of EI.

Previous studies demonstrated positive correlations between EI and cognitive performance, interpersonal communication skills, and patient satisfaction [8-11]. EI contributes to cognitive-based performance independent of general intelligence [12]. It has also been suggested that cognition and emotion are inextricably interwoven in complex decision making tasks, such as conflict detection and resolution [13]. Other studies have reported that students with higher EI had lower perceived stress $[14,15]$. An individual's ability to cope with stressful factors affects their perceived stress is independent of the number and quality of stressful factors [16]. Therefore, EI may play direct and indirect roles in medical nursing work [17]. The purpose of this study was to investigate and analyze the main work pressure of clinical practice nurses, improve their EI through targeted EI education, and shape good professional quality to actively cope with the work pressure.

\section{Methods}

\subsection{Participants}

A survey covering causes of job stress was distributed to 96 practice nurses who had just completed their internship. Participants' ages ranged from 20-24 years (mean $=22.61$ years, standard deviation $=0.99$ years). In addition, a sample of 102 practice nurses who participated in the internship program in our hospital from December 2015 to November 2016 was divided into an experimental group and a control group. Practice nurses in the experimental group were enrolled in EI training. Those in the control group received standard nursing teaching, which did not include EI training. Inclusion criteria were nurses: that consented to participate in the study, and agreed with the requirement to complete the EI questionnaires; had a full-time college degree or above; had no previous work experience; and had no mental illness or disturbance of consciousness. This study was approved by the Ethics Committee of our hospital. Informed consent was obtained from all participants.

\subsection{Job Stress Questionnaire}

First, a 35-item questionnaire (Appendix 1) designed by the present researchers was used to investigate causes of work pressure among practice nurses. The questionnaire comprised five parts: professional nursing knowledge, workload and time allocation, work environment and instrument/equipment problems, patient care and management, and interpersonal relationships. Responses for each item were on a scale from 0 (no pressure/stress) to 4 (serious pressure/stress); higher scores indicated a higher level of stress caused by that item. The questionnaire was anonymous. Participants independently completed the questionnaire according to their actual situation. In total, 89 of the 96 distributed questionnaires were returned; 88 questionnaires were valid (effective response rate of $98.9 \%$ ).

\subsection{EI Intervention and Instruments}

The EI training comprised six parts. The first part focused on strengthening professional beliefs. This aimed to build on nurses' professional education, guide them in a deeper understanding of the nursing profession, closely combine their development and nursing work, and establish a sense of professional pride. The second part focused on improving professional skills. This aimed to encourage nurses to work on their professional basics and develop nursing skills training programs, promote continued broadening of their horizons, and enhance their understanding and ability. The third part involved building participants' EI skill set. Participants learned skills to support managing bad moods, self-psychological adjustment, reasonable emotional catharsis, conscious control and elimination of negative emotions arising from the nursing process, and maintaining a positive mental state. The fourth part involved a seminar to inform development of EI education. The hospital's EI education curriculum was discussed in a clinical nursing case seminar focused on outstanding problems in clinical nursing work. The results were summarized, with the aim of broadening nurses' understanding and improving their ability to analyze and solve problems. The fifth part focused on nurturing communication skills. This aimed to encourage nurses to communicate more with patients, learn to care for and help patients, view problems from the perspectives of patients and their families, and give nurses skills to create good nurse-patient relationships. The final part covered psychological counseling agencies to support nurses' physical and mental health. This aimed to facilitate regular mental health seminars to teach nurse interns effective ways to alleviate psychological stress and improve their mental health.

The Chinese version of the Schutte Emotional Intelligence Scale (SEIS) was used to measure EI in both the control and the experimental groups at the start (Time 1) and end (Time 2) of the internship. The original version of the SEIS was developed by Schutte [18] to measure the level of EI skills among nurses. The Chinese SEIS comprises four items that assess an individual's ability to perceive, understand, express, control, and manage their own and others' emotions. Items are scored on a five-point Likert scale from 1 (Completely Disagree) to 5 (Completely Agree). Previous studies reported high Cronbach's alpha values for the SEIS [19, 20].

\subsection{Data Analysis}

Data were analyzed using SPSS version 18.0. Demographic variables for the experimental and control groups were compared using chi-square tests or independent samples t-tests. Independent samples t-tests and paired samples t-tests were used to examine EI scores for the control and experimental groups at Times 1 and 2. A $p$-value $<0.05$ was considered statistically significant. 


\section{Results}

Of the five dimensions in the job stress questionnaire, patient care ranked most stressful $(2.91 \pm 0.33)$, work load and time allocation was ranked second $(2.76 \pm 0.33)$, and work environment and equipment was ranked least stressful $(1.56 \pm 0.44)$ (Table 1). This indicated that work pressures on practice nurses were mainly caused by excessive nursing workloads and poor work time allocation.

Table 1. The score of probationer nurse work pressure causes.

\begin{tabular}{lll}
\hline Dimension & Number & Score \\
\hline Nursing professional knowledge & 88 & $2.68 \pm 0.29$ \\
Workload and time allocation & 88 & $2.76 \pm 0.33$ \\
Work environment and instrument and equipment & 88 & $1.56 \pm 0.44$ \\
Patient care & 88 & $2.91 \pm 0.33$ \\
Patient management and interpersonal relationship & 88 & $2.42 \pm 0.28$ \\
\hline
\end{tabular}

There were no significant differences between the control and experimental groups in terms of demographic characteristics at baseline (Table 2). The mean EI scores for the experimental and control groups at Time 1 were 3.27 and 3.29, respectively, and at Time 2 were 3.84 and 3.16, respectively (Figure 1). The mean work pressure score for the experimental group was 5.51 at Time 1 and 7.27 at Time 2 . The mean work pressure score in the control group was 5.98 at Time 1 and 11.69 at Time 2 (Figure 2). The mean EI scores increased from Time 1 to Time 2 in the experimental group, but not in the control group. Paired samples t-tests showed that these differences were statistically significant $(p<0.05)$. In addition, independent samples t-tests showed the difference in mean EI scores between the experimental and control groups at Time 2 was statistically significant $(p<0.05)$ (Table 3$)$.

Table 2. The study participants'demographic characteristics.

\begin{tabular}{llllll}
\hline Group & Number & Gender (Male /Female) & Age & Education (bachelor/college) & Residence place (Yes/No) \\
\hline Control & 51 & $3: 48$ & $21.33 \pm 0.93$ & $33: 18$ & $45: 6$ \\
Experiment & 51 & $4: 47$ & $21.41 \pm 0.98$ & $31: 20$ & $46: 5$ \\
Test statistics & & 0.000 & 0.414 & 0.168 & 0.102 \\
p-value & 1.000 & 0.680 & 0.682 & 0.750 \\
\hline
\end{tabular}

Table 3. The study participants' EI scores before and after the intervention.

\begin{tabular}{lllll}
\hline \multirow{2}{*}{ Group } & Number & EI Score & & Test statistics \\
\cline { 2 - 5 } & & Before & After & 3.293 \\
\hline Control & 51 & $3.29 \pm 0.22$ & $3.16 \pm 0.17$ & 17.840 \\
Experiment & 51 & $3.27 \pm 0.17$ & $3.84 \pm 0.17$ & 0.002 \\
Test statistics & & 0.491 & 20.177 & 0.000 \\
$p$-value & & 0.625 & & \\
\hline
\end{tabular}

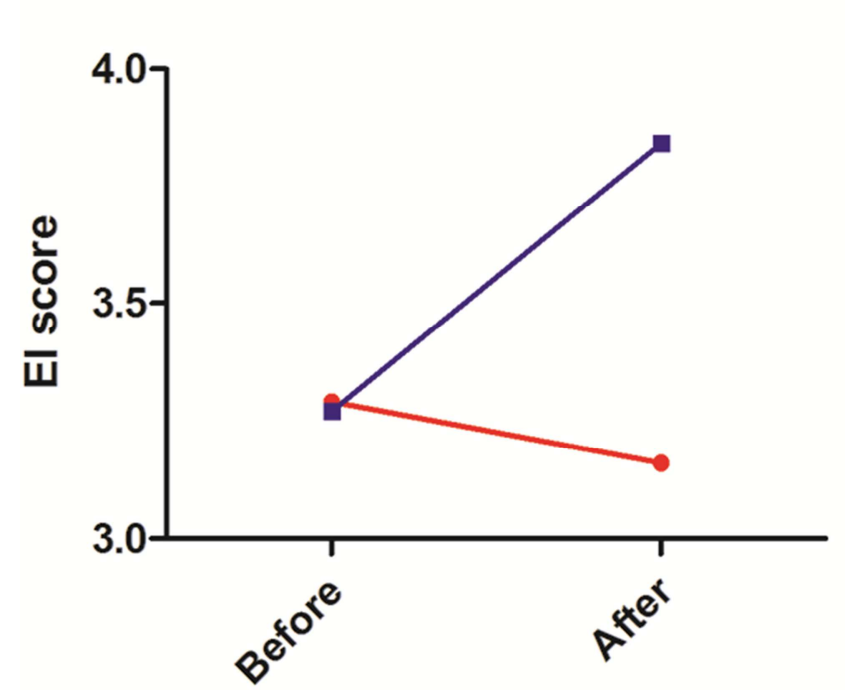

Control group

$\rightarrow$ Experiment group

Figure 1. The mean EI scores of the experimental and control groups at Time 1 and Time 2. 


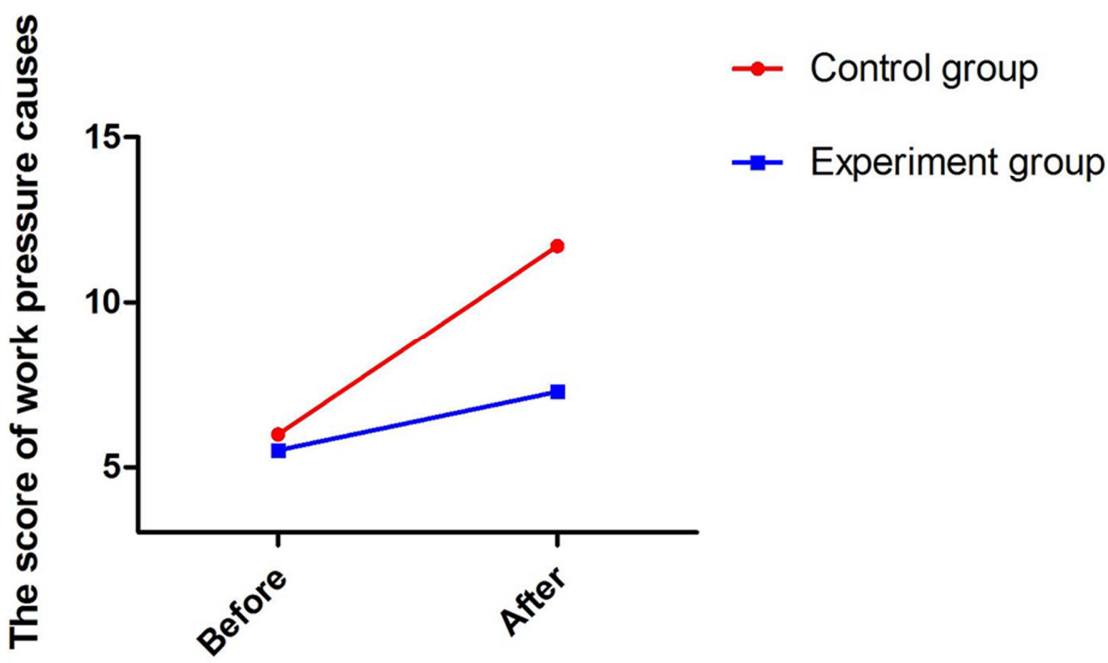

Figure 2. The mean work pressure score of the control group at Time 1 and Time 2.

\section{Discussion}

\subsection{Modern Nursing Work Requires a High Level of EI}

Nursing is considered one of the most stressful occupations. In addition to coping with heavy shift work, nurses need to skillfully manage nurse-patient relationships and conflicts [21, 22]. Low professional identity is also an important cause of psychological pressure for many nurses. A study conducted in 2017 examined the relationship between EI and nurses' caring experience, and reported that nursing students with higher trait EI scores were statistically more likely to complete training than those with lower scores [23]. Modern high-quality nurses have a solid foundation of professional knowledge and well-developed nursing skills, but they also need to develop strong psychological endurance and a mature mental state; that is, a high level of EI. Aithal [24] showed that EI is a necessary component of medical students' skill sets to ensure they are knowledgeable and academically competent in medical school and will also succeed in the future as quality healthcare professionals. Nurses with high levels of EI can maximize their subjective initiative, effectively control and regulate their emotions, actively take the initiative in coping with stress, solve problems, protect themselves more effectively, and ease potential nurse-patient conflicts [16]. Nurses' EI level has also been identified as a determinant factor for care behaviors [25].

\subsection{EI Education to Relieve Practical Nurses'Work Pressures}

Some previous studies showed that EI education carried out early during nursing professional learning had a more obvious effect [26]. Clinical practice is a starting point for nurses to apply theoretical knowledge to practical work. At the same time, it is also an important period for nurses to establish their values and outlook on life, shape their professional qualities, and acquire vocational skills. Therefore, high quality EI education is particularly important to develop comprehensive, high quality nurses. Our results showed that specific training greatly improved the EI of practice nurses, and may also overcome some work pressures.

Few studies have investigated the relationship between stressors and improving the level of EI among clinical practice nurses. Most previous studies focused on work and nursing students $[27,28]$. The main source stress among new clinical practice nurses in this study was patient care. The reason for such stress may be that the work experience and professional values of working nurses and practice nurses differ. In general, the social status of nursing staff is low, and nurses have lower pay and fewer benefits. Therefore, in-service nurses often lack momentum and motivation in their daily work, and job burnout is common. Key concerns relating to their day-to-day work include their salary, promotions, and post-graduate workloads. Practice nurses who have newly entered clinical practice often have strong self-esteem and weak psychological endurance, and may be prone to negative emotions in the face of difficulties and setbacks. Therefore, in the process of adapting to the clinical role of a nurse, the main pressures these nurses face may be adjusting their attitudes and correctly managing nurse-patient relationships. This should be considered when implementing EI training.

\subsection{Components of EI Training}

Nursing is a service, but is also a type of emotional labor. It requires nurses to use their physical strength and intelligence, but also requires emotional effort when they serve patients and their families. In the face of difficulties and setbacks, many nurses cannot understand and control their emotions, and may show depression, irritability, and impulsive behaviors. Through in-depth investigation and analysis of the main factors that affect stress among practice nurses, this study formulated a series of targeted measures to improve EI among nurses. The EI training focused on three main aspects: strengthening professional faith, improving professional skills, and developing EI education. First, nurses can only maintain their selfless dedication to their work by maintaining strong professional beliefs. Second, solid nursing skills and norms of nursing behavior can enhance the self-confidence of nursing 
students when starting work, and enhance their emotional and intellectual ability to provide patient care and protection. Finally, regular EI knowledge talks and seminars should be conducted to help nurses understand and master EI. In addition, hospitals and departments need to constantly implement measures to safeguard nurses' mental wellbeing. Education on patient management and humane care combined with clinical practice are important to develop EI skills among nurses; these three aspects complement each other and are indispensable.

\subsection{Study Limitations}

This study had some limitations. We only recruited 96 practice nurses to be surveyed about causes of their job stress. In a future study, we plan to expand the number of study participants. Furthermore, the researcher-designed questionnaire used in the study requires improvement.

\section{Conclusion}

EI education for practicing nurses is particularly important in supporting them to adapt to nursing work and build good nurse-patient relationships. However, EI training is still in the exploratory stage, and further large-scale studies are required to confirm our study findings.

\section{Acknowledgements}

We wish to thank all the probationer nurses who gave of their valuable time to participate in this study. This study was supported by the Chinese Anhui province Education Department key Fund Project (grant no. KJ2018A0252) and the Chinese Wuhu City Scientific and Technological Achievements Transformation Project (grant no. 2017CG27).

\section{Appendix}

\section{Appendix 1 Chinese Nurses' Job Stressor Scale}

\section{Questionnaire}

Hello, in order to better reduce the pressure for the nurses, we edited and produced this questionnaire. Please answer carefully. The content of the questionnaire will be kept confidential for you!

Personal information

Name:

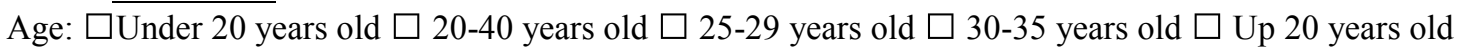

Education: $\square$ Secondary school $\square$ High school $\square$ College $\square$ Undergraduate $\square$ Master or above

Work experience: $\square$ 1-4years $\square$ 5-9 years $\square$ 10-14 years $\square$ 15-19 years $\square$ More than 20 years

Engaged in the working years for a nurse: $\square$ 1-2 years $\square$ 3-4 years $\square$ 5-6 years $\square$ 6-8 years $\square$ More than 8 years

Department (Please write the name of the department):

Telephone:

If the decompression group is carried out, hat is your expected time?

If your case is suitable for case work, would you like to do so? $\square$ willing $\square$ unwilling

Note::The following lists the problems that you may encounter. Please read each item carefully and make a judgement based on the following situation. Select one of the five numbers that represent different feelings and tick the box next. Please do it in 7 minutes!

Table 4. Job stress questionnaire.

\begin{tabular}{|c|c|c|c|c|c|c|}
\hline & & No & Slight & Medium & A bit serious & Serious \\
\hline 1 & The social status of nursing work is too low & & & & & \\
\hline 2 & There are few opportunities for further studies & & & & & \\
\hline 3 & Wages and other benefits are low & & & & & \\
\hline 4 & There are too few opportunities for promotion & & & & & \\
\hline 5 & Often shifts & & & & & \\
\hline 6 & Less independence at work & & & & & \\
\hline 8 & Too much work & & & & & \\
\hline 9 & The number of nurses at work is less & & & & & \\
\hline 10 & There is no time for psychological care of patients & & & & & \\
\hline 11 & Numerous non-nursing jobs & & & & & \\
\hline 12 & Too much useless written work & & & & & \\
\hline 13 & Poor working environment & & & & & \\
\hline 14 & Insufficient equipment needed in the work & & & & & \\
\hline 16 & Worried about mistakes in work & & & & & \\
\hline 17 & Nurses' work is not recognized by patients and their families & & & & & \\
\hline
\end{tabular}




\begin{tabular}{|c|c|c|c|c|c|c|}
\hline & & No & Slight & Medium & A bit serious & Serious \\
\hline 18 & Excessively ill patient & & & & & \\
\hline 19 & The patient's family is impolite & & & & & \\
\hline 20 & The patient's request is too high or too much & & & & & \\
\hline 21 & The patient is impolite. & & & & & \\
\hline 22 & Patients do not cooperate & & & & & \\
\hline 23 & The knowledge learned cannot satisfy the psychological needs of patients and their families & & & & & \\
\hline 24 & Lack of knowledge about patient education & & & & & \\
\hline 25 & Worry about nursing care can cause pain in the patient & & & & & \\
\hline 26 & The sudden death of the patient in the nursing & & & & & \\
\hline 27 & Lack of understanding and respect from other health workers & & & & & \\
\hline 28 & Insufficient understanding and support from nursing managers & & & & & \\
\hline 29 & Numerous criticisms of nursing managers & & & & & \\
\hline 30 & Doctors are picky about nursing & & & & & \\
\hline 31 & Lack of understanding and support among colleagues & & & & & \\
\hline 32 & Conflict with nursing manager & & & & & \\
\hline 33 & It is difficult to get along with some nurses & & & & & \\
\hline 34 & Conflict with doctor & & & & & \\
\hline 35 & Lack of friendly cooperation between colleagues & & & & & \\
\hline 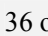 & ther problems: & & & & & \\
\hline
\end{tabular}

\section{References}

[1] Gorgens-Ekermans G, Brand T. Emotional intelligence as a moderator in the stress-burnout relationship: a questionnaire study on nurses. Journal of clinical nursing 2012; 21 (15-16): 2275-2285. doi: 10.1111/j.1365-2702.2012.04171.x.

[2] Garrosa E, Moreno-Jimenez B, Rodriguez-Munoz A, Rodriguez-Carvajal R. Role stress and personal resources in nursing: a cross-sectional study of burnout and engagement. International journal of nursing studies 2011; 48 (4): 479-489. doi: 10.1016/j.ijnurstu.2010.08.004.

[3] Quoidbach J, Hansenne M. The impact of trait emotional intelligence on nursing team performance and cohesiveness. Journal of professional nursing: official journal of the American Association of Colleges of Nursing 2009; 25 (1): 23-29. doi: 10.1016/j.profnurs.2007.12.002.

[4] Watson R, Deary I, Thompson D, Li G. A study of stress and burnout in nursing students in Hong Kong: a questionnaire survey. International journal of nursing studies 2008; 45 (10): 1534-1542. doi: 10.1016/j.ijnurstu.2007.11.003.

[5] Anthony M, Yastik J. Nursing students' experiences with incivility in clinical education. The Journal of nursing $\begin{array}{lllll}\text { education } & 2011 ; & 50 & \text { (3): } & 140-144\end{array}$ 10.3928/01484834-20110131-04.

[6] Evans W, Kelly B. Pre-registration diploma student nurse stress and coping measures. Nurse education today 2004; 24 (6): 473-482. doi: 10.1016/j.nedt.2004.05.004.

[7] Brackett MA, Salovey P. Measuring emotional intelligence with the Mayer-Salovery-Caruso Emotional Intelligence Test (MSCEIT). Psicothema 2006; 18 Suppl 34-41.

[8] Collins S, Andrejco K. A longitudinal study of emotional intelligence in graduate nurse anesthesia students. Asia-Pacific journal of oncology nursing 2015; 2 (2): 56-62. doi: $10.4103 / 2347-5625.157566$.

[9] Fernandez R, Salamonson Y, Griffiths R. Emotional intelligence as a predictor of academic performance in first-year accelerated graduate entry nursing students. Journal of clinical nursing 2012; 21 (23-24): 3485-3492. doi: 10.1111/j.1365-2702.2012.04199.x.

[10] Oyur Celik G. The relationship between patient satisfaction and emotional intelligence skills of nurses working in surgical clinics. Patient preference and adherence 2017; 11 1363-1368. doi: 10.2147/PPA.S136185.

[11] Wagner PJ, Moseley GC, Grant MM, Gore JR, Owens C. Physicians' emotional intelligence and patient satisfaction. Family medicine 2002; 34 (10): 750-754.

[12] Romanelli F, Cain J, Smith KM. Emotional intelligence as a predictor of academic and/or professional success. American journal of pharmaceutical education 2006; 70 (3): 69.

[13] Davidson RJ, Jackson DC, Kalin NH. Emotion, plasticity, context, and regulation: perspectives from affective neuroscience. Psychological bulletin 2000; 126 (6): 890-909.

[14] Naidoo S, Pau A. Emotional intelligence and perceived stress. SADJ: journal of the South African Dental Association = tydskrif van die Suid-Afrikaanse Tandheelkundige Vereniging 2008; 63 (3): 148-151.

[15] Pau A, Rowland ML, Naidoo S, AbdulKadir R, Makrynika E, Moraru R, et al. Emotional intelligence and perceived stress in dental undergraduates: a multinational survey. Journal of dental education 2007; 71 (2): 197-204.

[16] Por J, Barriball L, Fitzpatrick J, Roberts J. Emotional intelligence: its relationship to stress, coping, well-being and professional performance in nursing students. Nurse education today 2011; 31 (8): 855-860. doi: 10.1016/j.nedt.2010.12.023.

[17] Birks Y, McKendree J, Watt I. Emotional intelligence and perceived stress in healthcare students: a multi-institutional, multi-professional survey. BMC medical education 2009; 961. doi: $10.1186 / 1472-6920-9-61$

[18] Schutte NS, Malouff JM, Bobik C, Coston TD, Greeson C, Jedlicka $\mathrm{C}$, et al. Emotional intelligence and interpersonal relations. The Journal of social psychology 2001; 141 (4): 523-536. doi: 10.1080/00224540109600569. 
[19] Kim DH, Wang C, Ng KM. A Rasch rating scale modeling of the Schutte Self-Report Emotional Intelligence scale in a sample of international students. Assessment 2010; 17 (4): 484-496. doi: 10.1177/1073191110376593.

[20] Naeem N, Muijtjens A. Validity and reliability of bilingual English-Arabic version of Schutte self report emotional intelligence scale in an undergraduate Arab medical student sample. Medical teacher 2015; 37 Suppl 1 S20-26. doi: 10.3109/0142159X.2015.1006605.

[21] Blomberg K, Bisholt B, Kullen Engstrom A, Ohlsson U, Sundler Johansson A, Gustafsson M. Swedish nursing students' experience of stress during clinical practice in relation to clinical setting characteristics and the organisation of the clinical education. Journal of clinical nursing 2014; 23 (15-16): 2264-2271. doi: 10.1111/jocn.12506.

[22] Callaghan P. Organisation and stress among mental nurses. Nursing times 1991; 87 (34): 50.

[23] Snowden A, Stenhouse R, Duers L, Marshall S, Carver F, Brown $\mathrm{N}$, et al. The relationship between emotional intelligence, previous caring experience and successful completion of a pre-registration nursing/midwifery degree. Journal of advanced nursing 2018; 74 (2): 433-442. doi: 10.1111/jan.13455.

[24] Aithal AP, Kumar N, Gunasegeran P, Sundaram SM, Rong LZ,
Prabhu SP. A survey-based study of emotional intelligence as it relates to gender and academic performance of medical students. Educ Health (Abingdon) 2016; 29 (3): 255-258. doi: 10.4103/1357-6283.204227.

[25] Kaur D, Sambasivan M, Kumar N. Effect of spiritual intelligence, emotional intelligence, psychological ownership and burnout on caring behaviour of nurses: a cross-sectional study. Journal of clinical nursing 2013; 22 (21-22): 3192-3202. doi: $10.1111 /$ jocn. 12386 .

[26] Shanta L, Gargiulo L. A study of the influence of nursing education on development of emotional intelligence. Journal of professional nursing: official journal of the American Association of Colleges of Nursing 2014; 30 (6): 511-520. doi: 10.1016/j.profnurs.2014.06.005.

[27] Fujino Y, Tanaka M, Yonemitsu Y, Kawamoto R. The relationship between characteristics of nursing performance and years of experience in nurses with high emotional intelligence. International journal of nursing practice 2015; 21 (6): 876-881. doi: 10.1111/ijn.12311.

[28] Zhang P, Li CZ, Zhao YN, Xing FM, Chen CX, Tian XF, et al. The mediating role of emotional intelligence between negative life events and psychological distress among nursing students: A cross-sectional study. Nurse education today 2016; 44 121-126. doi: 10.1016/j.nedt.2016.05.025. 